\title{
Problem and Status Analysis of Urban Gas Supply Chains in China
}

\author{
Qunzhi WANG ${ }^{1,2}$ and Yuqing TANG $^{1,2}$ \\ ${ }^{1}$ School of Transportation and Logistics, Southwest Jiaotong University, Chengdu 610031, China \\ ${ }^{2}$ National United Engineering Laboratory of Integrated and Intelligent Transportation, Chengdu, 610031, China
}

\begin{abstract}
With the rapid development of economy and improvement of people's standard of life, there is an increasing demand for urban gas energy in China. The traditional pattern of urban gas supply chain in China now is distributed through urban gas company or directly to the downstream customers from gas suppliers such as Petro China, Sinopec and CNOOC. In this paper, after analyzing the traditional urban gas supply chain in China, we find that the performance is unsatisfied because the traditional mode is difficult to match the supply and demand very well for inflexibility. We propose that option contract can be introduced to the urban gas supply chain to deal with such problems. With options, the urban gas company can adjust order quantities according to the updated demand forecast, and transmit a portion of market risks to the urban gas company. The gas supplier, besides compensation from the revenue to sell options, can know the range of the adjustment, which is very important for the production decision. Since both the urban gas company and the gas supplier can benefit from options, and then the traditional operation mode of urban gas supply chain is improved.
\end{abstract}

Key Words : Urban gas supply, Supply contract, Flexibility, Options

\section{Introduction}

Since being environment-friendly and energy-saving, natural gas is favoured by customers. And socio-economic development also depends heavily on natural gas. As shown in the domestic and international oil and gas industry development report (2013) [2] released by the Petroleum Technology Research Institute of China, the population using urban gas grew from 210 million in 2012 to 240 million in 2013. The consumption of urban gas reached 68.7 billion cubic meters with an increase of $19.8 \%$, accounting for more than $40 \%$ of the total consumption. Since the consumption of urban gas is increasing fast, it is important to ensure the supply.

The major suppliers of urban gas in China are Petro China, Sinopec and CNOOC. China urban gas supply currently have two different modes, as shown in Fig. 1. One is urban gas company purchases gas from suppliers and sell them to downstream customers such as business, residents, small and medium enterprises. The other one is suppliers supply gas to end-users directly. Since the former one is the main supply mode in Chinese gas market, we consider it in this paper.

Generally, the urban gas companies are requested to sign supply contract with the gas suppliers for many years. However, the contracts between the urban gas companies and the end-users are often short-term contract. Consider a gas supply chain including a supplier, an urban gas company and an industrial end-user. At the end of the year, the industrial user may place an order for the next year according to his production

\footnotetext{
Corresponding Author: Qunzhi Wang

Department of Logistics Engineering, School of Transportation and Logistics, Southwest Jiaotong University, Chengdu, 610031 China

wangqunzhijp@yahoo.co.jp

(Received March 27, 2015)

(Revised May 20, 2015)

(Accepted May 25, 2015)
}

plan, and urban gas company ensures the gas supply. However, the gas suppliers will not allow the urban gas company to place order year after year. The gas supplier may require the urban gas company to place an order for a very long period, and any adjustment is not allowed. The long-term contract ensures a stable downstream market for the gas supplier. However, the gas demand of downstream market, especially for the demand in the future, is with high uncertainty for many reasons.

There are three main reasons: uncertain economic trends, urbanization speed, new energy development and utilization. The uncertain economic trends have large influence on production enterprises, which are main users for gas. They make production plan based on market demand which changes with the economic situation. Therefore, the uncertainty of the economic trends will affect the production quantity, and then the gas demand. On the other hands, the urbanization speed may causes the city' $s$ residence population to vary in the future. From a long-term perspective, the quantity of gas used by urban residents is with high uncertainty. Furthermore, the development and utilization of new energy may make end-users have more choices, which also lead to the uncertainty of gas demand in the future.

Apparently, the existing operation model of urban gas supply chain is simple and easy to operate, especially for the gas suppliers. Such operations mode makes it difficult for the urban gas company to match the long-term supply from the upstream enterprise and short-term demand from the downstream enterprise. If urban gas companies oversubscribed gas from suppliers, it not only occupies the social resources but also increases the storage cost. Whereas, if undersubscribed, it cannot satisfy the demand of users and influencing the development of local economy. This is a serious problem for the supply chain. Introducing supply contract may improve such problems. To the best of our knowledge, there is no literature on supply contracts for urban gas supply chains in China. In this paper, after 


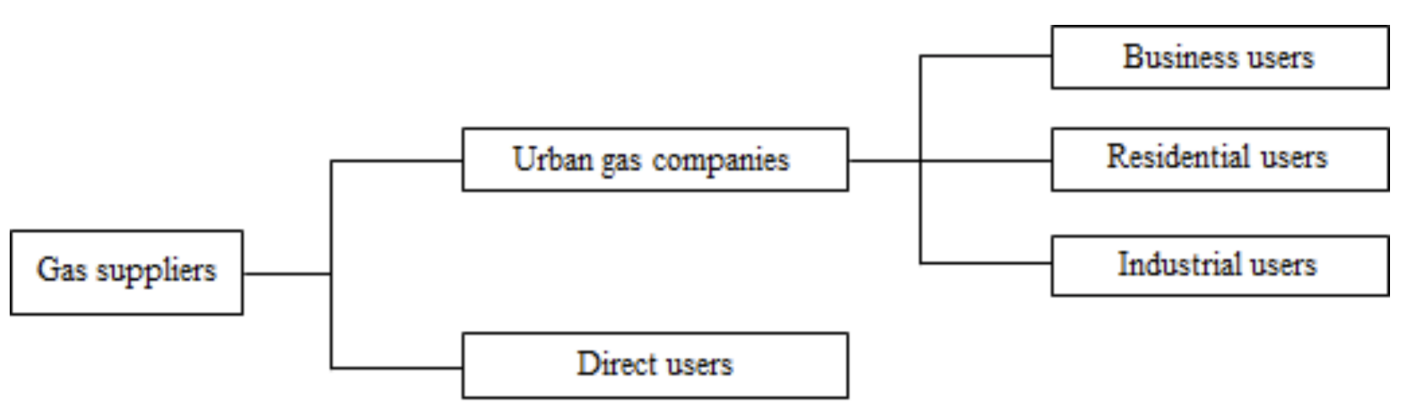

Fig. 1 Urban gas supply chain

analyzing the present situation and problems of the urban gas supply chain, we propose a flexible supply contract with options to cope with the demand uncertainty, which may improve the performance of the supply chain.

The rest of the paper is organized as follows. Section 2, we present a literature review. We analyze the status and problems of the current urban gas supply chain in Section 3. Section 4 analyzes several supply contracts and proposes a flexible supply contract with options into urban gas supply chain as a solution. Finally, the summary and suggestion are given in Section 5.

\section{Literature Review}

To improve the existing urban gas supply chain, scholars have carried out some researches. Xiao et al. (2010) [12] study the situation and problems of gas supply, and prove suggestions from the perspective of boosting the whole gas industrial chain coordinated development as well as gas supply security system. Zhang et al. (2011) [13] summary and evaluate the existing theoretical research into industrial chain of natural gas. They analyze the coordinated and comprehensive upgrading of gas industry chain, based on the characteristics of the gas industry. Zhao (2006) [14] take Tangshan city for an example, and suggest solving the gas shortage based on analysis of the status quo. Ali Azadeh et al. (2015) [1] proposing a multi-objective fuzzy linear programming model for optimization of gas supply chain through a greenhouse gas reduction approach from economic and environmental objectives.

However, as far as we know, there is little concerning solving the problem of urban gas supply chain through flexible contract model in a micro perspective in China. Flexible contract model can meet the wishes of the urban gas companies to order in a flexible amount, but will increase the supplier's production cost. Therefore, in order to attain this model where order is flexible, urban gas companies will be required to pay additional charges to the suppliers. The option is an important tool for the implementation of this cost transfer. As for option contracts, a lot of research has proved that option contracts can provide flexibility to cope with demand uncertainty and improve the performance of the supply chain.

Wang and Tsao (2006) [11] consider a flexible supply contract with call options model for an inflexible supply chain which the supplier has only one chance to produce. They get the explicit expressions to determine the buyer's optimal decisions, and calculate the supplier's optimal decisions. Finally, they prove that such a contract can improve both the buyer's and the supplier's profits. Wang and Zhang et al. (2012) [9] discuss the issue of supply chain coordination based on call option with two-stage. It is conclude that introduction of a call option contract may improve the flexibility of the supply system to respond to market changes. Li et al. (2012) [5] analyze the retailer' s stock, the optimal option strategies and the optimal production strategies of manufacturer in the background of price and market demand uncertainty. A conclusion was drawn that both sides can achieve win-win results with option contract price policy. Shang et al. (2013) [8] research on the two-stage production and order model in the case of call option. And they conclude that the flexible option contract can attain supply chain coordination. Ning et al. (2005) [7] study the option, which is completely independent of any supply chain contracts. They analyzed the optimal supply strategy of distributor when this kind of option is introduced. In addition, they discussed how option strengthens information flow and promote risk sharing, thus improving the efficiency of the supply chain. Wang and Tsao (2006) [10] build a single-period two-stage supply chain contract with bidirectional options. They explore the bidirectional option by which the option buyer can adjust freely the initial order quantity both upwards and downwards from the buyer's perspective. They also prove that the bidirectional options contract can improve the buyer's profit.

As is known, options improve supply chain flexibility, improving performance and have other advantages for the respective members. However, these studies only analyzed a single option contract, and they weren' $t$ applied to a specific industry. In this paper, after analyzing the present situation and problems of the urban gas supply chain from the microscopic point, we applies the option contract to the urban gas supply chain. It provides a solution to solve the problem due to urban gas supply chain insufficient flexibility.

\section{Status and problem analysis}

In the traditional supply chain system (see Fig. 2), urban gas companies sign long-term contract with suppliers. During the period of the long-term contract, the orders cannot be changed. This situation also be suitable for the short-term contract between urban gas companies and end-users. However, market demand for urban gas is easy to change. So that the traditional urban gas supply chains in China cannot match supply and demand very well because of urban gas demand uncer- 
tainty, which causes huge losses to urban gas companies and end-users.

On the one hand, in the traditional supply model, the urban gas companies have to fully consider the ordering and transporting amount along with its storage capacity. Take a coastal city for example, its special geographical location determines its heavy dependence on the transportation of urban gas from other areas. If urban gas companies subscribe too much gas, because the order quantity cannot be changed, it will cause excess inventory to urban gas companies. In addition, due to the features of gas, such as flammable and explosive, storage cost for gas is higher than other products. And the high storage cost places a heavy burden on the urban gas company. But if insufficiency, it cannot satisfy the needs of end-users, and affecting the development of local economy and people' $s$ life. At the same time, the urban gas company may lose its reputation. Hence, the traditional supply chain mode of the urban gas which brings huge inventory management difficulties to urban gas companies.

On the other hand, traditional gas supply model is also not conducive to end-users. Production enterprises, for example, sign short-term contract with urban gas companies according to production plan, which depends on the market demand. Furthermore, the market demand generally is determined by the economic situation. If the economic situation is arising, production enterprises will expand production and may lead to a larger gas demand than that in the contract. Because the order quantity cannot be revised, the urban gas companies has the right to stop gas supply. Meanwhile, it is hard to get replenishment from other places. Ultimately, it will bring huge loss to production enterprises. On the contrary, if not using up the gas amount in the contract, the production enterprises cannot do any adjustment and follow the take or pay clause on the basis of contract, which may also cause huge loss for production enterprises.

\section{Solution analysis}

Based on the above analysis, we can learn that the traditional urban gas supply chains in China cannot match supply and demand very well. In response to the plight of urban gas supply chain, the commonly method is supply contract including whole-sale price contract, buy-back contract, revenue-sharing contract, option contract and so on. Those contracts with flexibility increase the flexibility of the supply chain in order to respond to market demand uncertainty, and may reduce the inventory risk of the buyer. Due to the different characteristics and range of application of different contract models, it is necessary to compare and select the most suitable model for urban gas supply chain.

The wholesale price contract is the most common and simple one. In this model, the supplier only provides a wholesale price, and the buyer places order according to the demand forecast. Receiving the order from the buyer, the supplier starts the production and deliver finished products at the beginning of the selling season. Then, the buyer sells products to customer, and any products left over, buyer takes the risks of overstock or understock. In reality, the wholesale price contract is widely used because it is very simple to implement. However, it has been proved that such contracts may lead to bad performance for supply chains because of its inflexibility. Buy-back contracts and revenue-sharing contracts are two kinds of contracts to provide flexibility to supply chains.

Buy-back contracts is similar with the wholesale price contracts. The difference is that the supplier will provide a buyback price besides the wholesale price [4]. And at the end of the selling season, the supplier can buy back the products left over from the buyer. However, according to the characteristics of gas, buy-back contract is not applicable. One main reason is that it is difficult to return and store the gas once it has been delivered.

With the revenue-sharing contract, the buyer shares a portion of the selling price to the supplier in return for a lower wholesale price [6]. Under the revenue-sharing contract, the supplier must monitor the buyer' $s$ revenues to verify that they are split appropriately [3]. Such contracts, widely used in videocassette rental industry, require relatively transparent earnings between companies in a supply chain. However, not all of the urban gas companies and the gas suppliers want to share the earnings with each other.

Option gives the buyer the right, but not the obligation, to adjust initial order at a predetermined price just before the supplier's delivery, one for each option. There are many kinds of options such as call option, put option, bidirectional option and deferral option etc., which can be widely used in urban gas supply chain. Call option and put option can be used to adjust the initial order quantity in one direction (upward or downward), while bidirectional option for two directions. Deferral option is the right to delay the start of a project.

Different from buy-back contracts, option contracts allow the buyer to adjust the order adjustment before the delivery. Thus, for the urban gas supply chain, with option contracts, the urban gas company needs not to return gas back to the supplier. On the other hand, option contracts also do not require the urban gas company and the gas supplier to share the earnings. Therefore, we propose option contracts in the urban gas supply chain.

In the option contract model, the gas supplier provides option contract including the wholesale price, option price and option exercise price. The urban gas company purchases gas from supplier and sells to end-user. In addition to the initial order, the urban gas company can buy options to adjust the initial order in the future if necessary. Events in option contract model have the following sequence (see Fig. 3). At the beginning of the planning horizon ( $\mathrm{t} 0$ ), the urban gas company decides how much gas to order initially and how many options to purchase according to preliminary demand forecast. And the supplier produces gas to satisfy the possible supply quantity. Between t0 and the time of delivery ( $\mathrm{t} 1)$, urban gas company collects information to update demand forecast. At t1, usually from the beginning of the year, the urban gas company adjusts the initial order by exercising options. And the supplier starts to deliver the gas according to the urban gas company' s order. Any adjustment without option is not allowed. At the end of the contract ( $t 2)$, holding cost occurs if left over.

Both the urban gas company and the gas supplier can benefit from options. For the urban gas company, purchasing options can make it possible to take full advantages of the gas production period to continue to collect market information so as to update the demand forecast. With the updated forecast, urban gas company can use option to adjust order quantities to respond to market fluctuations, which may reduce the losses from 


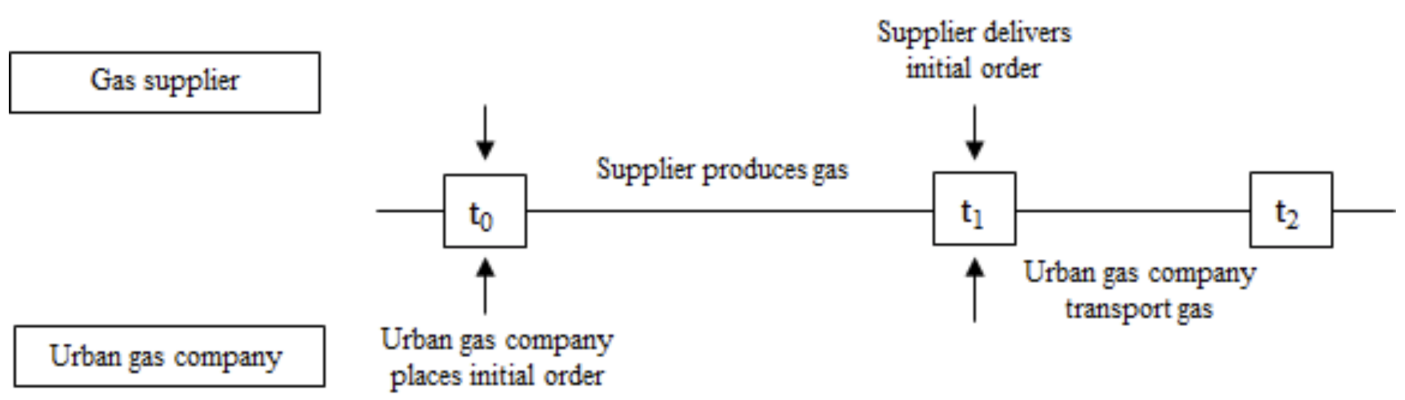

Fig. 2 A time line of the urban gas supply for the traditional model

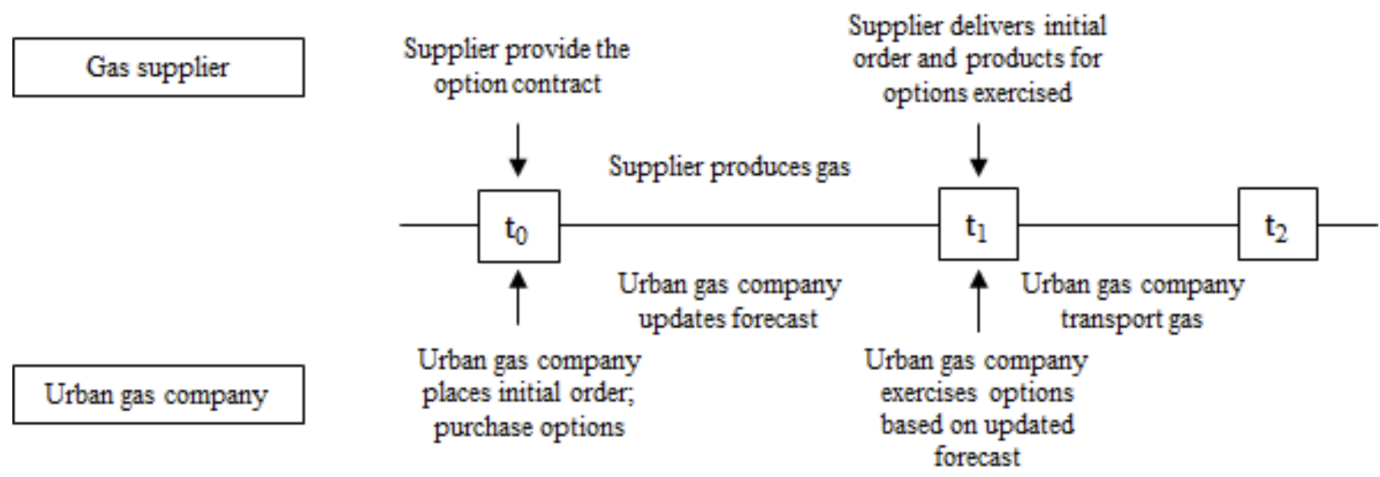

Fig. 3 A time line of the urban gas supply for the option contract model

future uncertain demand. Since unit option price is lower than the wholesale price, the gas supplier, in fact, undertakes a portion of market risks together with the urban gas company. For the gas supplier, with option contracts, she can be compensated from the revenue to sell options. And since having known the range of the adjustment, the gas supplier can make thorough preparation to make different supply plans beforehand. On the other hand, compared with the traditional supply mode, it has been proved that using options can increase the buyer' $s$ order quantity, from which the supplier also can benefit [12]. Because introducing options leads to a win-win relationship for both players, the performance of the whole urban gas supply chain also has been improved.

\section{Conclusion}

In this paper, after analysing the traditional urban gas supply chain in China, we find that the performance is unsatisfied because the traditional mode is difficult to match the supply and demand very well for inflexibility. We propose that option contract can be introduced to the urban gas supply chain to deal with the demand-supply mismatch.

Both the urban gas company and the gas supplier can benefit from options, and then the traditional operation mode of urban gas supply chain is improved. With options, the urban gas company can adjust order quantities according to the updated demand forecast, and transmit a portion of market risks to the urban gas company. The gas supplier, besides compensation from the revenue to sell options, can know the range of the adjustment, which is very important for the production decision.
For the future work, one can apply option contracts into a real urban gas supply chain and prove whether and to what extent the option contract can improve the traditional urban gas supply chain or not quantitatively.

\section{References}

[1] Ali A., Zeinab R., and Mansour Z., 2015. A multi-objective fuzzy linear programming model for optimization of natural gas supply chain through a greenhouse gas reduction approach, Natural Gas Science and Engineering, 26, 702-710 .

[2] Qian X. K., and Jiang X. F., Domestic and International Oil and Gas Industry Development Report(2013), Version 1, Bei Jing, Economic Research Institute of China National Petroleum Corporation Technology , 2014, 124-149.

[3] Gerard P. C., and Martin A. L., 2005. Supply Chain Coordination with Revenue-Sharing Contracts: Strengths and Limitations, Management Science, 51(1), 30-44.

[4] Hamilton E., and Stephen M. G., 2013. Note. The Role of Returns Policies in Pricing and Inventory Decisions for Catalogue Goods, Management Science, 44(2), 276-283.

[5] Li L., and Fang T., 2012. The coordination of Option Contract with two-stage supply chain under uncertain environment, Systems Engineering, 27(6), 812-822.

[6] Nicola B., Ilaria G., Pierpaolo P., and Christopher S.T., 2006. The implications of joint adoption of revenue sharing and advance booking discount programs, International Journal of Production Economics, 121(2), 383-394.

[7] Ning Z., and Dai J., 2005. The application of option in supply chain risk management, Systems Engineering Theory and Practice, 22(7), 49-54.

[8] Shang W., and Qi M., 2013. The demand forecast information real-time updates of supply chain flexibility option coordination contract, Journal of Management, 10(12), 1847-1854. 
[9] Wang L., and Zhang J., 2012. Analysis of Supply Chain Coordination based on flexible options contract, Bohai University (Natural Science), 33(1), 92-96.

[10] Wang Q., and Tsao D. B., 2006. Supply contract with bidirectional options: the buyer's perspective, International Journal of Production Economics, 707(1), 30-52.

[11] Wang, Q., Tang, O., and Tsao D. B., 2006. A flexible contract strategy in a supply chain with an inflexible production mode, International Journal of Operational Research, 7(3), 228-248.

[12] Xiao Y., and Hu N., 2011. The Problems and Solutions of China's natural gas supply security, Daqing Social Sciences, 169(6), 80-82.

[13] Zhang W., 2013. Research on the Coordinated Development and Upgrade of Natural Gas Industry Chain, Dissertation Submitted of China University of Geosciences.

[14] Zhao L., 2006. Proposal of shortage gas supply situation, Gas \& Heat, 26(9), 33-34.

\section{Acknowledgments}

This research is supported in by the National Social Science Foundation of China (No. 13CGL056), Development Research Center of Oil and Gas, Sichuan (SKB13-07).

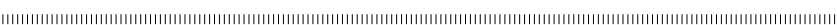

\section{Qunzhi WANG (Member)}

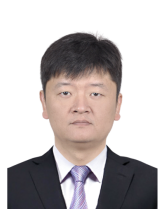

is associate professor of logistics engineering in Southwest Jiaotong University. He received his $\mathrm{PhD}$ degree from Tokyo Institute of Technology in 2005, and worked for the industry for several years. Dr. Wang has published in the International Journal of Production Economics, Journal of Japan Industrial Management Association, International Journal of Operational Research, and other scientific journals. His research interest includes supply chain management, logistics planning

\section{Yuqing TANG}

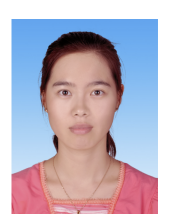

is an assistant project leader of the "Research on the Application of Flexible Supply Contracts in Urban Gas Supply Chains". Her research interests include supply chain management and logistics planning. 